\title{
De Tristes Trópicos à palavras de um Xamã Yanomani, a coleção Terra Humana de Jean Malaurie pela Editora Plon: Uma Grande Coleção De Ciências Sociais À Escuta Do Mundo*
}

\author{
Jean-Yves Mollier \\ Universidade de Versailles Saint-Quentin-en-Yvelines \\ Centro de história cultural das sociedades contemporâneas
}

A coleção Terra Humana dirigida por Jean Maulaurie festejará em 2014 seus sessenta anos de existência sob a direção do mesmo homem que, em 1955, oferecia a leitura de Tristes Tropiques (Tristes Trópicos), a reportagem etnográfica de Claude Lévi-Strauss publicada nessa biblioteca. Ele mesmo vinha de publicar, meses antes, Les Derniers Rois de Thulé (Os Últimos Reis de Thulé), obra na qual ele alertava o mundo sobre os perigos que ameaçavam os povos Inuit do norte da Groenlândia. A tradução de Carnets indiens (Cadernos indígenas) de Darcy Ribeiro, em 2002, foi um evento, assim como havia sido a reedição, em 1998, do livro publicado quarenta anos antes por Roger Bastide, Le candomblé de Bahia (O candomblé de Bahia). Em 2010, o lançamento de um volume intitulado La chute du ciel. Paroles d'un chaman Yanomani (A queda do céu. Palavras de um xamã Yanomani) de Davi Kopenawa, o líder dos Índios do Brasil, confirma o interesse permanecido intacto do editor da coleção mais prestigiosa das ciências humanas francesas por um país de que seu amigo Claude Lévi-Strauss lhe havia precocemente mostrado a espantosa riqueza e revelado a diversidade cultural. Se acrescentarmos que essa destacada biblioteca também inscreveu Les veines ouvertes de l'Amérique latine (As veias abertas da América Latina) de Eduardo Galeano no seu catálogo em 1981, que ela fez conhecer os costumes dos Urubu antropófagos do Norte do Brasil, com Aimables Sauvages (Amáveis Selvagens), em 1960, e os das populações da Amazônia publicando, em 1968, Yanoama, o relato de Helena Valero que viveu vinte e dois anos nessa região, sem contar a Chronique des 
Indiens Guayaki (Crônica dos Índios Guayaki) do Paraguai levantada por Pierre Clastres em 1972, compreendemos que estamos em presença de uma coleção completamente excepcional cuja gênese e sua inscrição no ambiente científico europeu ${ }^{2}$ merecem ser reconstituídas.

As bibliotecas, compreendidas no sentido de depósitos de manuscritos e em seguida de livros, têm uma longa história, simbolizadas pelo desaparecimento e a sequente reconstrução da Biblioteca de Alexandria no Egito. A publicação das Règles du bibliothécaire (Regras do bibliotecário) pelos beneditinos de Saint-Maur, a grande abadia parisiense, em 1663, marca uma data e anuncia uma outra abordagem e a repartição dos fundos documentais, mais próxima de nossas preocupações. Todavia deve-se chegar ao extremo fim do século XVII para se ver nascerem autênticas coleções de livros portando o nome de 'bibliotecas', o que acrescenta ao sentido inicial aquele que vai se impor para o qual podemos chamar as 'bibliotecas sem tetos e muros'. Roger Chartier enumerou trinta e uma para o período que se estende de 1686 a $1789^{3}$, data que representará uma ruptura já que o grande século da coleção será o XIX ${ }^{4}$, antes que o aparecimento do livro de bolso, no século seguinte, multiplique as ocasiões ${ }^{5}$. Dentre as mais célebres, citaremos a Biblioteca Charpentier surgida em 1838 e a Biblioteca das estradas de ferro de Louis Hachette ${ }^{7}$, nascida em 1853, pois uma e outra correspondem a uma massificação do público leitor e a disponibilização à maioria de livros à baixo preço, 3 francos 50 ou 15 euros no primeiro caso e 1 franco ou 5 euros no segundo. Muito rapidamente, ao lado de coleções de romances que são corriqueiros nos anos 1830-1870, outras séries veem o dia, tal qual a Biblioteca das maravilhas de Edouard Charton ${ }^{8}$ em 1864 que une a magia à vulgarização científica.

No domínio das ciências humanas, deverá se esperar o pós-Segunda Guerra Mundial para ver surgirem verdadeiras coleções orientadas segundo princípios coerentes pois, na editora de Albert Savine ou na de Pierre-Victor Stock, na virada dos séculos XIX e XX, uma Biblioteca sociológica reúne ainda todos aqueles que pretendem contestar ou reorganizar a sociedade, Bakounine, Kropotkine, Louis $\mathrm{Michel}^{9}$, o que não deixará de surpreender o leitor do século XXI, acostumado a outras classificações do pensamento, para não dizer a outras representações mentais. Enquanto que em Paris as Presses Universitaires de France (Imprensa Universitária da França), nascidas em 1921 e reestruturadas em 1939 após sua absorção de três fundos de edição que

\section{Maracanan}


encheram seu catálogo, lançam em 1941 a coleção enciclopédica Que sais-je? ${ }^{10}$, os editores de literatura geral começam, no início dos anos 1950, a se agrupar em ordem de batalha para encarar o universo movimentado das ciências sociais. $\mathrm{O}$ desenvolvimento do marxismo, aquele do estruturalismo, a notoriedade de Jean-Paul Sartre e do existencialismo, os progressos fulgurantes da sociologia assim que da antropologia alimentam a curiosidade do público culto que não pretende permanecer à margem dos debates públicos. Grandes revistas, Esprit (Espírito), Les Temps modernes (Os Tempos modernos), Critique (Crítica), La Pensée (O Pensamento), propagam as discussões e as controvérsias que ocorrem no meio acadêmico ${ }^{11}$, o que explica porque, nos anos 1970, Roland Barthes, Michel Foucault, Louis Althusser, Jacques Derrida e alguns outros grandes intelectuais poderão aparecer aos olhos do estrangeiro como os pais da French Theorie ${ }^{12}$. Os Brasileiros não haviam esperado o pós-guerra para se familiarizar com os trabalhos da jovem escola de ciências sociais e estarão dentre os primeiros a traduzir os volumes lançados na coleção Terra Humana de que convém agora examinar a especificidade.

\section{Terra Humana na Editora Plon, um fenômeno tipicamente francês}

Esperaríamos, com efeito, ver essa biblioteca especializada aparecer no catálogo de um editor situado próximo à Sorbonne, à faculdade de medicina ou dos jovens institutos de pesquisa que se desenvolvem no pós-guerra, a VI seção da Escola Prática de Altos Estudos, a matriz da Escola de Altos Estudos em Ciências Sociais, por exemplo, mas tal não ocorre e é ao contrário numa 'velha dama adormecida', a austera e muito maurrassiana casa editorial Plon, a editora das Memórias de Churchill, de Guderian, do general De Gaulle e do marechal Joukov que «Terra Humana » verá o dia em fins de $1954^{13}$. Jean Malaurie contou várias vezes a milagrosa e inusitada ascensão de um editor que nada destinava a essa intrusão no domínio da antropologia mas que bem tinha suas razões em fazer esquecer sua complacência com o regime de Vichy, nem que para isso devesse fazer apelo à jovens agitadores, a partir do momento em que eles não flertassem muito ostensivamente com o marxismo. Na Liberação, de fato, o campo editorial francês havia subido graves perturbações. Os novos chegados nesse meio, tais como as Edições de Minuit de Vercors, aquelas do Seuil, de Emmanuel Mounier, ou as casas editoriais fundadas por 
Edmond Charlot, o primeiro editor de Albert Camus, e alguns outros provinham da Resistência e esses recém-chegados estavam decididos a expurgar a profissão das ovelhas ranhosas que haviam aceitado muito facilmente a lei alemã e o nazismo. Bernard Grasset iria perder sua empresa, Robert Denoël sua vida, e Gaston Gallimard temeu por um momento pagar as consequências da entrada de Drieu La Rochelle à direção da NrF. Quanto à sociedade Plon, Nourrit e Cie, muito comprometida com Vichy, ela aderiu tardiamente às novas autoridades e ela beberá o cálice até à amargura quando ela editará as Mémoire de guerre (Memórias de guerra) do general De Gaulle, ela que havia publicado textos do marechal Pétain e assumia plenamente a defesa dos valores encarnados pela Revolução nacional que o primeiro tinha combatido ${ }^{14}$.

Felizmente para os seus dirigentes, o homem político que havia encarnado a França Livre em 1940 iria rapidamente deixar o poder após haver recusado, no início de 1946 a continuar a dirigir um governo no qual o Partido Comunista era todo-poderoso e ele iria parecer aos olhos da direita de seu país como a muralha contra a revolução, o que só podia tranquilizar e até seduzir Maurice Bourdel, o diretor-geral da sociedade. Para fazer calar seus detratores e amansar os juízes que deviam examinar a atitude de sua firma durante a guerra, ele havia empregado no final de 1944 Charles Orengo, um resistente de última hora que, ele também, queria ocultar o fato de que ele havia sido remunerado como censor pelo regime de Vichy e que havia tido êxito se atribuindo um falso diploma de resistente aprisionado por suas ideias ${ }^{15}$. Inteligente, à espera da novidade, grande leitor e verdadeiro editor no sentido de descobridor de talentos ainda não revelados é ele que acolheu em 1954 um jovem explorador voltando de uma expedição no grande Norte, Jean Malaurie, que lhe fez um relato muito excitante de seu encontro com os Inuit. A ideia de lhe confiar uma coleção de livros que teria um caráter científico incontestável e uma qualidade de escrita que lhe daria um parentesco com a ficção havia florescido em seu cérebro após ouvi-lo. Já que a aventura em mundo distante atraía os leitores desde meados do século XIX e que numerosas obras, do gênero Le Tour du monde ( $A$ Volta ao mundo) e o Journal des voyages (Jornal das viagens) haviam sedimentado o terreno de múltiplas séries de romances, dos quais "As viagens extraordinárias" de Jules Verne, pela editora Hetzel, era o exemplo típico, nada se opunha à recriação de um espaço editorial para esse tipo de literatura ${ }^{16}$. Num pós-guerra onde

\section{Maracanan}


a conquista espacial ainda não estava na ordem do dia e onde a guerra fria e o confronto dos dois grandes faziam temer pelo pior, oferecer uma tribuna a aventureiros dotados de uma bagagem científica suficiente podia ser uma excelente iniciativa.

O encontro entre Jean Malaurie e os anciões enfarpelados de audiofonos que compunham, segundo sua maliciosa reconstituição, o conselho de administração das edições Plon, desembocou num contrato limitado aos poucos livros que encontraram simpatia aos seus olhos, Les Derniers Rois de Thulé (Os Últimos reis de Thulè) e Tristes Tropiques (Tristes Trópicos) em 1955, Les Immémoriaux (Os Imemoriais) em 1956, Afrique ambigüe (África ambígua) de Georges Balandier em 1957 e Sol hopi de Don C. Talayesva em 1959. Com seus cinco volumes inseridos no catálogo em cinco anos, o resultado era magro e convém então evitar propor uma reescritura hagiográfica de uma coleção que, manifestamente, não entusiasmava os proprietários nem o gerente da casa editorial Plon mas que conservava a confiança do diretor, preocupado em modernizar a firma e de fazer vir à ela autores que renovariam o fundo ${ }^{17}$. $\mathrm{Na}$ medida em que os dois primeiros títulos haviam sido bem acolhidos pela crítica e em que traduções estavam em curso, a casa editorial não podia senão se felicitar do faro de Charles Orengo. Para o lançamento de Tristes Trópicos, ela havia mesmo visto o júri do Prêmio Goncourt se rasgar num comunicado para explicar que ele lamentava o fato de que o regulamento de sua academia impunha de recompensar um romance pois, se eles tivessem tido liberdade de seu voto, os jurados teriam coroado o livro de Claude Lévi-Strauss. Lembrar as circunstâncias exatas da publicação desse clássico da etnologia, é destacar o parentesco genérico desse estudo com a reportagem e mesmo com a ficção. Jean Malaurie havia insistido junto ao seu colega para que lhe dessem outra coisa ao invés de uma tese ou do que uma brochura destinada aos meios eruditos. Ele mesmo tinha-se de bom grado dobrado a essa regra quanto ele havia contado sua experiência e sua vida junto aos Inuit. Propondo um relato capaz de manter o fôlego do leitor, ele sabia que tomava o risco de desagradar aos mandarins que dirigiam a Sorbonne mas era consciente do fato de que um sucesso público e uma imprensa elogiosa não deixariam de influenciar no julgamento de seus pares.

Penetramos por esse viés na fábrica editorial da coleção Terra Humana e percebemos que ainda que ela se situe bem no domínio das ciências sociais, 
ela dele se distingue por certas características que a aparentam ao romance e explicam porque é uma casa editorial dita de literatura geral que a abrigou e não uma empresa especializada situada no polo não comercial do campo. Jean Malaurie queria como Pierre Nora em história ou Michel Foucault em psicologia, sua disciplina universitária inicial, quebrar os códigos em vigor e penetrar com estrondo na cidadela acadêmica e eles o conseguiram ao favor das circunstâncias, a França da Quarta República favorecendo essas mutações do campo intelectual. A massificação do ensino superior, a ascensão das classes médias, o crescimento econômico, todos esses fatores contribuíam à mudança e como existia precedentes célebres, a Vie de Jésus (Vida de Jesus) de Renan ou Le Peuple (O Povo) de Michelet, todos dois professores no Colégio de França mas igualmente autores de livros que se tinham vendido muito bem e haviam servido à sua notoriedade, os editores e os meios eruditos não podiam se indignar ao ver essa mistura de gêneros ou essa confusão de universos perturbar seus hábitos. No início do século XX, havia mesmo se visto um médico sem verdadeiros diplomas, Gustave Le Bon, dirigir na casa editorial Flammarion a Biblioteca de filosofia científica e atrair para esse editor muito voltado para o grande público tudo o que a Universidade contava como celebridades acadêmicas. Longe de se aparentar às coleções publicadas pelas imprensa universitária de Cambridge, de Oxford ou de Columbia, de Harvard, de Princeton ou de Yale, Terra Humana se situava assim logo numa tradição francesa a meio caminho entre o público erudito e o público culto, o que não podia deixar de contribuir para sua midiatização.

\section{Um catálogo representativo das curiosidades de seu diretor}

Quando folheamos o catálogo da coleção Terra Humana ou que observamos o estudo que dela fizemos, para o período 1955-2000, Pierre Aurégan, e que ele intitulou Des récits et des hommes. Terre Humaine : un autre regard sur les sciences de l'homme (Relatos e homens. Terra Humana: um outro olhar sobre as ciências do homem), verificamos o caráter eclético de uma biblioteca sem outras fronteiras do que aquelas que lhe são fixadas pelo humor vagabundo de seu diretor. Uma contagem rápida dos títulos que compõem a série mostra também que, contrariamente ao que ele pôde escrever ou dizer, Jean Malaurie não teve tanta liberdade como gostaria de ter tido. Ele inclusive frequentemente

\section{Maracanan}


reconheceu que Maurice Bourdel não queria Victor Segalen em sua editora porque ele o julgava invendável ${ }^{19}$. Com cinco títulos publicados nos cinco primeiros anos e em seguida dez volumes nos dez anos seguintes, Terra Humana contava apenas quinze títulos em 1969 e vinte e cinco em 1975, o que a condenava quase que certamente ao desaparecimento. Nenhuma outra coleção, com efeito, quer seja das ciências exatas quer seja das ciências sociais, da ficção ou de um outro gênero, pode justificar sua existência quando ela não consegue atingir um título por ano em média. É o sucesso prodigioso do Cheval d'orgueil (Cavalo de orgulho), o relato de um professor bretão que fazia revier, com verdadeiro talento de contador o passado de sua região, suas tradições, suas crenças e seu patrimônio ameaçados pela modernidade, que devia estabilizar definitivamente a presença de Jean Malaurie junto à casa editorial Plon e mesmo lhe assegurar doravante o status invejado de diretor de coleção trazendo dinheiro para o seu editor. A época favorecia a narrativa, e, na casa editorial Fayard, "Os Novos Estudos históricos" vinham de ser relançados no momento onde elas estavam prestes a desaparecer, graças à popularidade de uma biografia, a de Louis XI, que Paul Murray Kedall havia oportunamente resgatado do esquecimento. Utilizando os recursos de Walter Scott e dando espessura aos seus personagens, ele provava àqueles que duvidavam que a história podia ainda fazer sonhar e que o campo científico não era um domínio reservado aos especialistas ${ }^{20}$.

A lista das vinte e cinco primeiras obras inscritas no catálogo de "Terra Humana " mexe com a imaginação se recolocamos sua presença numa casa editorial particularmente marcada politicamente e sempre nostálgica do regime de Vichy. A leitura de Afrique ambigüe (África ambígua) de Georges Balandier só podia chocar as concepções de dirigentes patronais para os quais a colonização havia escrito uma das páginas mais gloriosas da história da França e que sentiam apenas desprezo em relação aos líderes indígenas que aspiravam a tomar o poder e a se substituir ao homem branco. De fato o autor não era conhecido como um agitador nem um etnólogo particularmente engajado mas seu livro não deixava dúvida alguma sobre suas preferências e suas certezas quanto ao futuro do continente negro. Também Terres vivantes (Terras vivas) de René Dumont, publicado em 1961, se não é ainda um hino à ecologia, descreve com simpatia os camponeses do terceiro mundo que o agrônomo cruzou ao longo de suas viagens pelo planeta. Dois anos mais 
tarde, Jean Malaurie provocava rebuliço oferecendo, em tradução, quatro estudos do antropólogo Margaret Mead, que, bem antes dos trabalhos de Judith Butler, riscavam de introduzir a turbulência no gênero já que seu livro, Mours et sexualité en Océanie (Costumes e sexualidade na Oceania), destacava a relatividade dos papéis masculinos e femininos em certas populações. De fato a autora tinha se tornado a referencia por excelência em matéria de antropologia mas se leitores começassem a imaginar que o que era admitido nas sociedades da Oceania o poderia ser um dia no Ocidente, a casa editorial Plon passaria por uma oficina perigosa, o que fazia felizmente sorrir aqueles que liam as declarações de seus dirigentes, sempre preocupados em respeitar a moral e em publicar apenas autores como François Mauriac, Paul Claudel ou Gabriel Marcel ${ }^{21}$.

Como o diria publicamente Maurice Bourdel à jornalista que o interrogava a respeito de Les Nouvelles littéraires (As Notícias literárias em 1952): "Nós temos sempre em mente uma espécie de agrupamento dos escritores de talento tendo um ideal comum de defesa da civilização ocidental" e, para ter certeza de ser bem compreendido, acrescentava: "De fato, a linha da casa é muito simples: encorajar e fazer conhecer os escritores de qualidade, preocupados em defender as cores eternas da civilização humanista e cristã, no sentido o mais elevado e mais largo do termo ${ }^{22}$ ". De forma um tanto surpreendente, ele concluía que isso predispunha a sua casa editorial a recrutar os jovens autores e os originais e citava aleatoriamente Marguerite Yourcenar, para as Mémoires d'Hadrien (Memórias de Hadriano), François Mauriac e Henri Troyat assim que Mouloud Mammeri, mas esse último estava solidamente enquadrado pelo médico eugênico Alexis Carrel, de cujo escritor Plon havia vendido centenas de milhares de exemplares de L'Homme, cet inconnu (O Homem, esse desconhecido), Mazo de La Roche para a série das Jalna e o Romeno anticomunista Virgil Gheorghiu, cuja obra La Vingt-cinquième heure (A Vigésima-quinta hora) havia obtido uma enorme repercussão em 1949. Tipo de eco às revelações de Arthur Koesteler que, em Le Zéro et l'Infini (O Zero e o Infinito), publicado pela Camann-Levy, havia denunciado as perversidades do sistema soviético, o relato de Gheorgiu ilustrava a vontade das editoras Plon, Nourrit e Cia de permanecer sobre bases ideológicas que a maioria dos volumes retidos por Jean Malaurie contestava. A reação epidérmica de Maurce Bourdel face ao romance de Victor Segalen, Les Immémoriaux (Os

\section{Maracanan}


Imemoriais), traduz bem sua recusa de admitir que o cristianismo e a colonização tenham podido numa região tão remota como a Polinésia, assanhar-se em destruir uma civilização tão bela como a dos Maoris.

Un village anatolien (Uma aldeia anatoliana) de Mahmout Akal ou Un substitut de campagne en Egypte (Um substituto de campanha no Egito) de Tewfik El Hakim deviam suscitar menos problemas porque, nessas duas investigações, o Islã era descrito sem complacência, mas a casa editorial Plon se reconhecia mal na maioria dos títulos que, ano após ano, reforçava o catálogo de Terra Humana e dela faziam verdadeiramente uma coleção à parte no domínio das ciências humanas. A atração pelas sociedades rurais não desagradava particularmente a uma firma orientada para o passado mas Sol hopi, de Don C. Talayaesva, Ishi, de Theodora Kroeber, Piegan de Richard Lancaster, e Louons maintenant les grands hommes (Louvemos agora os grandes homens) de James Agee para o texto e Walker Evans para as fotografias estavam a cem léguas das preocupações de dirigentes patronais que ficavam sediados há anos nos conselhos de administração de seu sindicato, que haviam pertencido ao Comitê de organização do Livro instalado pelos serviços do marechal Pétain e que se tinham reconciliados com a democracia apenas ao ver o general De Gaulle, após 1958, atacar duramente a esquerda e o Partido comunista com o qual ele havia caminhado em1944-1945. A entrada de Jacques Soustelle, em 1967, para Les Quatre Soleils (Os Quatro Sóis), era mais tranquilizadora aos seus olhos pois o etnólogo que havia sido resistente havia passado do gaullismo militante à Organização Exército secreto, após 1961, e havia tido que se exilar para escapar à prisão ${ }^{23}$. Com isso, é o campo progressista que compreendeu mal porque Jean Malaurie acolhia na sua coleção um homem que se tinha totalmente distanciado de seus estudos mexicanos e que parecia aproveitar a ocasião para reabilitar, sem o dizer, sua concepção estática da evolução das sociedades humanas.

Dois outros livros haviam certamente causado choque na casa editorial Plon: Des affaires de famille (Negócios de família) de Francis A.J. Ianni, uma reportagem sociológica sobre a máfia nos Estados Unidos na qual o autor se proibia qualquer julgamento de valor, e Suas Prisões, de Bruce Jackson, obra prefaciada por Michel Foucault e consagrada ao universo carcerário americano. Mais do que o tema que poderia ser aceito, era a palavra dada aos "bichas e cafetões" na terceira parte do volume que não passava. Jean 
Malaurie tinha prazer de invocar a tradição do romance francês, Balzac que, em Splendeurs et misères des courtisanes (Splendores e misérias das cortesãs), havia colocado em cena o submundo e os excluídos, ou Jean Genet e seu Journal d'un voleur (Jornal de um ladrão). Todavia este último era precisamente um autor da Gallimard acusado de favorecer os homossexuais, brutalmente denunciados como 'pederastas', e Plon nunca teria pensado em fazê-lo entrar na casa que o general De Gaulle havia preferido à Gallimard e a Robert Laffont, em 1958, quando tinha se tratado de publicar o primeiro volume de suas Memórias de guerra. Guardiã de uma tradição e, nesse sentido, mais preocupada do que outras em manter uma coerência ideológica em seu catálogo, a casa editorial Plon, Nourrit e Cia não se assemelhava às suas jovens concorrentes que não buscavam outra coisa a não ser falar delas, como a casa Julliard que lançará Françoise Sagan, ou as Presses da Cité (Imprensa da Cidade) que deitavam o olho sobre a América para preparar coleções vistosas suscetíveis de agradar aos leitores transformados em simples consumidores. Independente e familial, rica e sem preocupação material antes de 1960, a firma implantada a dois passos da igreja e do seminário Saint-Sulpice havia mesmo investido fundos no pontapé inicial das Edições da Távola Redonda, uma empresa situada muito à direita do cenário político ${ }^{24}$, o que explica que às vésperas da publicação do Cavalo de orgulho, em 1975, a situação de Jean Malaurie tenha piorado ao seio de uma sociedade para a qual Terra Humana fazia figura de peixe fora d'água ou de OVNI, isto é de coleção totalmente à parte que não havia outra justificativa senão o desejo dos dirigentes de conservar um pé num setor onde elas não podiam rivalizar nem com as PUF, nem com Seuil ou Gallimard.

Todavia, Maurice Bourdel tinha se retirado sem herdeiro varão e havia cedido sua sociedade a um banco que a revendeu ao presidente-diretor geral das Presses de la Cité, Sven Nielsen, um Dinamarquês que havia realizado polpudos lucros com a coleção Le Fleuve noir (O Rio negro) e que, aproveitando as circunstâncias, estava forjando-se um império no pequeno mundo da edição francesa de meados dos anos 1960. Tendo comprado Plon, Perrin, Julliard, 10-18 e muitas outras casas editoriais, ele deixava os homens que ele havia recrutado para o secundar e dirigir suas sociedades e Jean Malaurie beneficiou de uma pausa que lhe permitiu continuar a publicar os autores de que gostava ${ }^{25}$. Charles Orengo havia brutalmente sido afastado e aquele que

\section{Maracanan}


o substituiu, Marcel Jullian, era um romancista e paralelamente um cenarista de televisão que, bem que monarquista, não deixava seus sentimentos ditar suas decisões. Levado pelo financista proprietário a rentabilizar sua nova entidade jurídica, Plon-Perrin, ele teria sem dúvida sido levado a suspender Terra Humana e a deixar a coleção morrer de sua bela morte, se o sucesso, o dissemos, de 'Cavalo de orgulho', não o tivesse convencido de que o inclassificável e original Jean Malaurie podia ainda se mostrar capaz de fazer falar dele e da casa editorial que o abrigava há vinte anos. Nesse sentido, as circunstâncias pesaram de um peso grande em 1975 para perenizar uma biblioteca científica absolutamente fora do comum que, como suas análogas das ciências humanas, estava ameaçada pelo sucesso das coleções de bolso e, notadamente, por '10-18', uma série cujo nome evoca as pequenas dimensões (dez centímetros sobre dezoito) e, portanto, o baixo preço. Referendado pelos estudantes que, após 1968, compram sistematicamente seus volumes, aqueles dos Essais (Ensaios), pela Gallimard, Point Histoire (Ponto História) pela Seuil ou seus equivalentes, essa coleção então dirigida por Christian Bourgois pertence também à Sven Nielsen e ela poderia ter, se observamos de perto seu catálogo, introduzido a maioria dos títulos de Terra Humana no seu fundo se os 300.000 exemplares do livro de Pierre-Jakez Hélias, O carvalho de orgulho, não a tivessem momentaneamente salvo ${ }^{26}$.

\section{Terra humana de 1975 ao raiar do III milênio}

O catálogo comportava vinte e cinco títulos em 1975 e sessenta e um em 1995, o que significa que o aumento não foi muito importante já que a média anual atinge apenas dois volumes e deve-se dar razão a Jean-Claude Dubost que, por ocasião do colóquio do cinquentenário, em 2005, rendia homenagem tanto à perspicácia de Charles Orengo como à de Bernard de Fallois, o novo presidente-diretor geral que, em 1982, decidiu duplicar Terra Humana com a coleção Terre Humaine Poche (Terra Humana Bolso) que lhe deu uma garantia que ela nunca havia possuído ${ }^{27}$. Entretempo, L'Eté grec (O Verão grego) de Jacques Lacarrière, Le Grand Métier (A Grande Profissão) - sobre a pesca do bacalhau - Toinou de Antoine Sylvère - a história de um meeiro de Auvergne - e Gaston Lucas, serrurier (Gaston Lucas, serralheiro) de Adélaïde Blasquez haviam acrescentado às crônicas do planeta e aos cadernos de 
inquérito dos etnólogos o relato da vida dos simples, um pescador, um pastor ou um serralheiro reunindo-se ao camponês na pintura da grandeza do cotidiano. Incontestavelmente, essas escolhas constituem bem o horizonte pessoal do diretor e conferem à sua coleção uma unidade que ninguém pensaria lhe contestar. Recusando o culto do progresso, a conquista espacial e todos os hinos entoados por outros aos construtores de represas ou aos engenheiros que revolucionavam então os hábitos e os modos de vida dos homens, Jean Malaurie se situa, alguns diriam, na vanguarda do que fará o cerne do movimento ecológico nos anos 1980, ou à retaguarda dirão outros observando que seus heróis são essencialmente rurais, marginais ou excluídos da civilização. Sensível muito cedo ao desaparecimento programado dos povos mais vulneráveis, Jean Malaurie conferiu aos seus livros essa coloração que deles faz, não obras militantes, ainda menos de propaganda, mas sim testemunhos, acessíveis ao grande público, e também convites para meditar sobre a evolução de nossas sociedades ${ }^{28}$. Nem adiante nem atrás mas sim não convencional, o antropólogo amigo dos Inuit dá a palavra nesses anos 1970-1980 àqueles que lhe parecem capazes de dizer verdades perturbadoras e de descrever com humildade sua vida e a daqueles ao seu redor.

Abrindo cada vez mais o compasso, o diretor da coleção « Terra Humana » dá a ler relatos da vida rural concernente a Mesopotâmia com Les Arabes des marais (Os Árabes dos pântanos) de Wilfred Thesiger, o campesinato húngaro mais pobre e mais distanciado da cultura escrita, com Le vinaigre et le fiel (O vinagre e o fel) de Marget Gari, mas ele volta aos seus temas favoritos dando novamente a palavra a Bruce Jackson,com Le Quartier de la mort (O Bairro da morte), à René Dumont, com Pour l'Afrique, j'accuse (Pela África, eu acuso) cujo título explica talvez porque o volume seguinte será Carnets d'enquête d'Emile Zola (Os Cadernos de inquérito de Emile Zola) que será vendido além das esperanças de seu prefaciador, Henri Mitterand. Le Horsain, itinerário de um padre estrangeiro no país de Caux para onde ele é enviado, inaugura uma escuta dos problemas que perpassam a Igreja católica e que desembocarão num grande livro, Quand Rome condamne (Quando Roma condena), de François Leprieur, um antigo padre intimado, como seus irmãos, a escolher entre permanecer na Igreja e renunciar ao seu apostolado na usina ou a conservar sua nova profissão e se proibir o acesso aos sacramentos. Mineur de fond (Mineiro) de Augustin Viseux, espécie de Germinal do século

\section{Maracanan}


XX mas escrito por um contramestre, portanto um agente de direção e não um operário, encontrará ele também os favores do público.Outros volumes, consagrados ao Japão - La Maison Yamazaki (A Casa Yamazaki) de Laurence Caillet - ao Sul tunisiano, Chebika de Jean Duvignaud - ou Un village russe (Uma aldeia russa) testemunham da variedade das paisagens que entram uns após os outros numa série que parece se dar por tarefa encerrar a diversidade do mundo físico e captar o olhar de todas as populações e de todos os grupos humanos ameaçados de desaparecimento mais ou menos próximos ${ }^{29}$.

Muito presente desde o segundo volume, Tristes Trópicos, o Brasil é sem dúvida alguma o país mais bem representado nessa coleção já que após Amáveis Selvagens de Francis Huxley, em 1960, Yanoama de Ettore Biocca em 1968, Chronique des Indiens guayaki (Crônica dos ìndios guayaki) de Pierre Clastres em 1972, Les veines ouvertes de l'Amérique latine (As veias abertas da América Latina) de Eduardo Galeano em 1981, esses dois últimos títulos ultrapassando o quadro único do Brasil, Les lances du crépuscule (As lanças do crepúsculo) de Philippe Descola em 1994, Le Candomblé de Bahia (O Candomblé da Bahia) em 1999 formam um grupo importante de sete livros dedicados aos Índios da Amazônia ou às populações que residem no interior das fronteiras do Brasil. A esse grupo relativamente homogêneo, acrescentaremos as obras que dão a palavra aos Índios da América, de Soleil hopi à De mémoire indienne, pois eles completam a visão pessoal de Jean Malaurie sobre as populações indígenas, próximas de uma certa maneira dos Inuit aos quais ele dedicou igualmente vários volumes. Convém mencionar, para sermos completos, os livros sobre o shtetl da Europa central, os campos de concentração - Sachso - e a Shoah Du fond de l'abîme (Do fundo do abismo) de Hillel Seidmann - pois eles nos parecem igualmente reveladores de uma autêntica política editorial elaborada ao longo dos anos por um científico percorrendo o mundo e dirigindo um grande laboratório de pesquisa onde ele recruta uma parte de seus autores ao mesmo tempo em que fica à escuta do universo no qual ele vive afim $O$ cavalo de orgulho havia feito de seu autor, mas também por respingo, seu 'editor' dos personagens mediáticos e a atuação da televisão grande público havia dado à coleção Terra Humana uma audiência que ela nunca havia possuído anteriormente. Três anos mais tarde, Jean Malaurie decidiria imitar as Edições do Seuil e publicar um Bulletin Terre Humaine (Boletim Terra Humana) destinado a fazer conhecer os novos títulos da série e a fidelizar uma clientela cada vez 
mais volátil. Todavia, é a proposta de Bernard de Fallois, presidente-diretor geral do grupo Plon-Perrin desde 1975 e artesão da batedura miditática que fez impulsionar as vendas do Cavalo de orgulho até um milhão de exemplares, que convenceu Jean Malaurie a deixar de lado suas prevenções contra o 'Bolso' e a se lançar numa nova aventura. Tendo conseguido se tornar o verdadeiro patrão da nova coleção Terra Humana Bolso, portanto a conservar o poder de escolher seus títulos, ele adentrava, a partir de 1982, o público dos estudantes, cada vez mais ligado a essas únicas séries bom mercado de volumes e mais preocupado com leituras relacionadas com seu universo profissional do que a geração dos que haviam 'feito' 1968. Com esse segundo suporte, a coleção conheceu um novo sopro, reeditando títulos que haviam particularmente bem funcionado, Tristes Trópicos, Os Últimos Reis de Thulé, O cavalo de orgulho e O verão grego, mas acrescentando todos os novos volumes da série. Assim, ao invés de serem tentativas isoladas como o haviam sido Tristes Trópicos, A África ambígua, Os Últimos Reis de Thulé, Os Imemoriais e La Mort sara (A Morte sara), os únicos volumes que Jean Malaurie havia consentido, sem poder agir diferentemente, a fazer entrar na coleção '10-18' entre 1962 e 1971, a passagem sistemática da coleção mãe na série de sua filha vai consolidar a posição do editor ${ }^{30}$ e lhe fazer ganhar a confiança dos novos patrões de um grupo de edição que, de 1975 a 2005, conhecerá múltiplos proprietários ${ }^{31}$.

Além da coleção Terra Humana Bolso e dos nove Boletins Terra Humana que são publicados de 1978 a 1985, dois álbuns foram acrescentados aos volumes - Visions d'um nomade (Visões de um nômade) de Wilfred Thesiger e Ultima Thulé de Jean Malaurie - assim como cinco obras de uma série intitulada Courants de Pensée (Correntes de pensamento) - Henri Mitterand, Jacques Lacarrière, René Dumont, Jean Duvignaud e Michel Ragon - o que, lá ainda, contribui a solidificar a base editorial e midiática de uma coleção que se orgulhará, em 2000, após quarenta e cinco anos de existência, de ter vendido dez milhões de exemplares ${ }^{32}$, isto é, em média, 222.000 volumes, a cada ano, o que mexe evidentemente com a imaginação e reforça o caráter mítico, ou, em todo caso, atípico, de uma série que podemos de fato colocar no rol das ciências humanas já que o homem está ao centro das preocupações de todos os autores que nela figuram, mas que, por suas qualidades estilísticas e o tom imposto aos relatos, está situada no coração das estratégias de escrita próprias às grandes casas de edição

\section{Maracanan}


literária. Essa impressão é reforçada pelas confidências de certos autores que confessam de bom grado que seu diretor lhes obrigara a reescrever cinco ou seis vezes seu manuscrito, a retomar seu trabalho, como se tivesse se tratado do texto de um romance. Agindo como qualquer grande 'editor' dirigindo uma casa de edição objetivando a consagração literária, a atribuição de prêmios e de recompensas, artigos nas revistas, entrevistas no rádio e na televisão, Jean Malaurie conseguiu atingir seu objetivo: divulgar homens e mulheres, mas preferencialmente os primeiros, cuja vida é uma lição ou um testemunho sobre um mundo em vias de desaparecimento. É sem dúvida sua grande força já que ele festejará no final de 2014 o sexagenário aniversário do contrato que o vincula às editoras Plon - evidentemente um recorde absoluto neste universo - mas também o que termina de fazer dele um ser totalmente à parte na edição das ciências humanas.

Para concluir esse painel consagrado à existência surpreendente de uma «biblioteca " científica, insistiremos sobre sua ancoragem incontestável no terreno dos hábitos e dos costumes próprios ao campo cultural francês. Não podemos imaginar caso equivalente inglês ou americano para este tipo de coleção pois a organização do campo intelectual é diferente nesses dois países onde a imprensa das grandes universidades são o local privilegiado de acolhimento dos trabalhos que Jean Malaurie reuniu em sua coleção. Naturalmente a personalidade do 'editor' desempenhou um nítido papel no seu sucesso, sua capacidade de estabelecer relações no mundo político, midiático ou entre os líderes de opinião em geral sendo excepcional. $\mathrm{O}$ antigo presidente da República, Jacques Chirac, era fascinado pelo personagem e o convidada de bom grado ao Eliseu. A URSS e depois a Rússia honraram o pesquisador e o defensor incansável dos povos do grande Norte. Os Estados Unidos e grande número de outros países igualmente contribuíram para o seu brilho. Tudo isto ajudou, em retorno, o editor na sua tarefa, mas, para além do homem e do seu imenso talento, deve-se admitir que uma tal coleção, Terra Humana, sem dúvida a mais bela vitrine do Brasil no mundo acadêmico europeu, apenas poderia nascer num país onde o campo cultural permanece o local de confrontos entre forças que o ultrapassam consideravelmente e lhe proíbem esta autonomia que, aliás, o rende de fato mais independente mas o priva dessas possibilidades de intervenção na esfera política que é - ou era? - a grande característica dos intelectuais franceses no século XIX.

Janeiro | Dezembro 2012 
Notas e Referências

*Versão traduzida por Inoã Pierre Carvalho Urbinati.

2 Ver Pierre AUREGAN, Des récits et des hommes. Terre Humaine : un autre regard sur les sciences de l'homme (Relatos e homens. Terra Humana: um outro olhar sobre as ciências do homem), Paris, Nathan/Plon, 2001, para uma análise sistemática dessa coleção e Terre Humaine. Cinquante ans d'une collection (Terra Humana. Cinquenta anos de uma coleção), dir. Mauricette BERNE et JeanMarc TERRASSE. Paris : BnF, 2005, para um estudo à múltiplas entradas.

3 Roger CHARTIER. L'ordre des livres. Lecteurs, auteurs, bibliothèques en Europe entre XVIe et XVIIIe siècle (A ordem dos livros. Leitores, autores, bibliotecas na Eruropa entre o século XVI e o século XVIII), Aix-en-Provence: Alinéa, 1992, p. 74 .

4 Isabelle OLIVERO. L'invention de la collection : de la diffusion de la littérature et des savoirs à la formation du citoyen au XIXe siècle ( $A$ invenção da coleção : da difusão da literatura e dos saberes à formação do cidadão no século XIX), Paris: IMEC Ed., 1999.

5 Du'poche' aux collections de poche. Histoire et mutations d'un genre (Do 'bolso' ás coleções de bolso. História e mutações de um gênero). dir. Jean-Yves MOLLIER e Lucile TRUNEL, Liège, Céfal, Les Cahiers des paralittératures n 10, 2009.

6 Isabelle OLIVERO. op.cit.

7 Jean-Yves MOLLIER. Louis Hachette (1800-1864). Le fondateur d'un empire (Louis Hachette 1800-1864. O fundador de um império). Paris : Fayard, 1999.

8 Marie-Laure AURENCHE. Edouard Charton et l'invention du "Magasin pittoresque » (1833-1870) (Edouard Charton e a invenção da "Revista pitoresca 18331870). Paris : Honoré Champion, 2002.

9 Jean-Yves MOLLIER. Un éditeur dreyfusard : Pierre-Victor Stock ( Um editor dreyfusard :Pierre-Victor Stock ), L'affaire Dreyfus (O caso Dreyfus) dir. Michel WINOCK, Paris : Seuil, 1998, p. 195-201.

10 Valérie TESNIERE. Le Quadrige. Un siècle d'édition universitaire. 1860-1968 (A Quadriga. Um século de edição universária, 1860-1914). Paris, PUF: 2001, p. 331-339.

11 Dictionnaire des intellectuels français (Dicionário dos intelectuais franceses). dir. Jacques JULLIARD e Michel WINOCK. Paris : Seuil, 2002.

12 Ver sobre essa gênese os trabalhos de François DOSSE, notadamente sua Histoire du structuralisme (História dos estruturalismos), Paris : La Découverte,

\section{Maracanan}


1992, 2 vol., e La marche des idées. Histoire des intellectuels, histoire intellectuelle (A marcha das idéias. História dos intelectuais, história intelectual), Paris, La Découverte, 2003, assim que L'histoire des intellectuels aujourd'hui (História dos intelectuais de hoje), dir. Michel LEYMARIE et Jean-François SIRINELLI. Paris: PUF, 2003.

13 Jean-Yves Mollier. "Une aventure éditoriale hors des sentiers battus", in Terre Humaine. Cinquante ans d'une collection (Terra Humana. Cinquenta anos de uma coleção), op.cit., p. 129-140.

14 Jean-Yves MOLLIER. Edition, presse et pouvoir en France au XXe siècle (Edição. Imprensa e poder na França no século XX). Paris: Fayard, 2008.

15 Ibidem.

16 Matthieu LETOURNEUX e Jean-Yves MOLLIER. La Librairie Tallandier. Histoire d'une grande maison d'édition populaire (1870-2000) (A Livraria Tallandier. História de uma grande casa de edição popular (1870-2000). Paris: Nouveau Monde éditions, 2011, e Sylvain VENAYRE. La gloire de l'aventure (A glória da aventura). Paris: Aubier, 2002.

17 Pierre AUREGAN. op. cit.

18 Benoît MARPEAU. Gustave Le Bon. Parcours d'un intellectuel 1841-1931 (Gustave Le Bon. Percurso de um intelectual 1841-1931). Paris : CNRS Editions, 2000.

19 Jean MALAURIE. "Entretien avec Hélène Willemart” ("Entrevista com Hélène Willemart”), Pour Jean Malaurie (Para Jean Malaurie). Paris : Plon, 1990, p. 773 et sqs.

20 Philippe OLIVERA. "Edition d'histoire ", Historiographies. Concepts et débats (Historiografias. Conceitos e debates), dir. Christian DELACROIX, François DOSSE, Patrick GARCIA et Nicolas OFFENSTADT. Paris : Gallimard, coll. "Folio Histoire", 2010, 2 vol., T. II, p. 112-123.

21 Jean-Yves MOLLIER. Edition, presse et pouvoir en France au XXe siècle (Edição, imprensa e poder na França no século XX). op. cit.

22 Edith MORA. "Editeurs, qui êtes-vous ? A la Librairie Plon" ("Editores, quem sois? Na Livraria Plon”), Les Nouvelles littéraires (As Notícias Literárias), 27 novembro 1952, e Jean-Yves Mollier, op. cit., para um estudo dessa série de reportagens sobre a edição francesa.

23 Bernard DROZ. "Soustelle, Jacques", Dictionnaire des intellectuels (Dicionário dos intelectuais). op.cit., p. 1306-1307.

Janeiro | Dezembro 2012 
24 Jean-Yves MOLLIER. Edition, presse et pouvoir en France au XXe siècle (Edição, imprensa e poder na França no século XX). op. cit.

25 Ibid.

26 Ibid.

27 Jean-Claude DUBOST e François LAURENT. "De Terre Humaine à Terre Humaine Poche" ("De Terra Humana à Terra Humana Bolso"), Terre Humaine. Cinquante ans d'une collection (Terra Humana. Cinquenta anos de uma coleção). op. cit., p. 144-148.

28 Pierre AUREGAN. op. cit.

29 Ibid.

30 Ibid.

31 Jean-Yves MOLLIER. op.cit.

32 Pierre AUREGAN. op. cit. 